ارزيابى عملكرد دستخاه WFD در تعيين اجزاى بيلان آب نفوذ يافته به ناحيه ريشه

مصطفى رئيسى اسدآبادى"، محمدرضا نورى امامزادهئى و روحالله فتاحى نافيى'

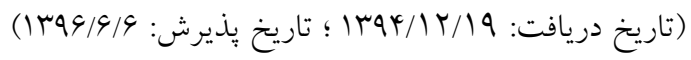

جكيده

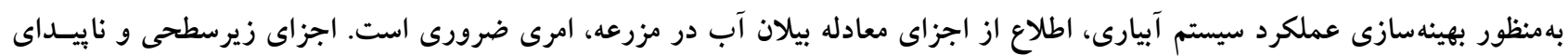

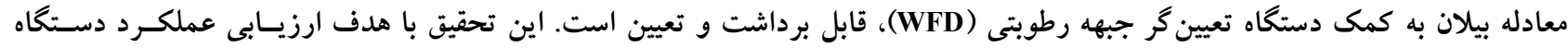
WFD

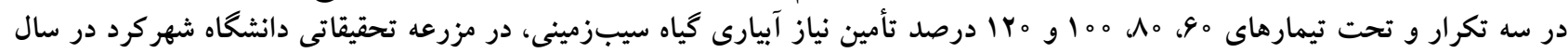

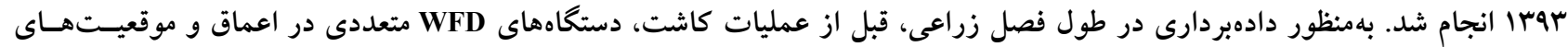

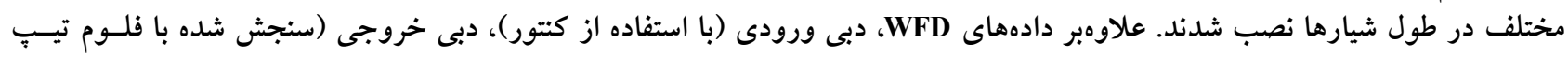

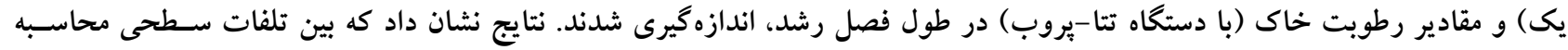

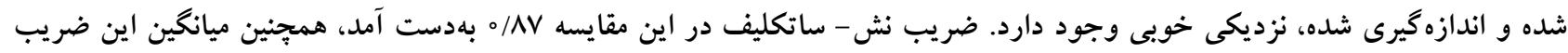

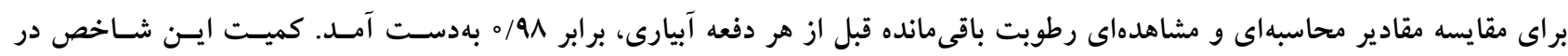

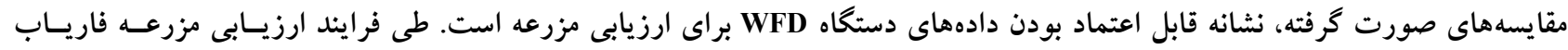

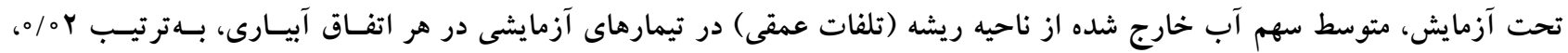

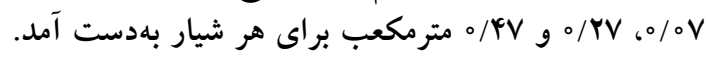

وازمهاى كليدى: بيلان آب، تلفات سطحى، تلفات عمقى

1 ا. كروه مهندسى آب، دانشكده كشاورزى، دانشگاه شهركرد

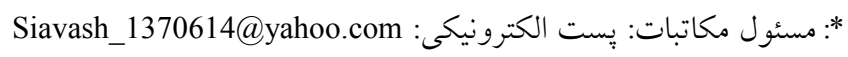


اين دستكاه (شكل (1) بهو كونهاى است كه در يك تـراز معسين در عمق خاك جنان نصب مى شودكه قسمت ورودى قيف آن كاملاً

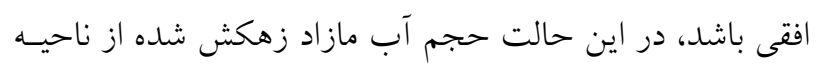

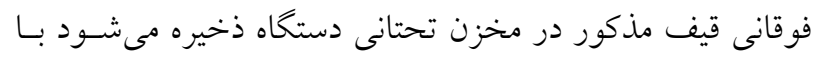

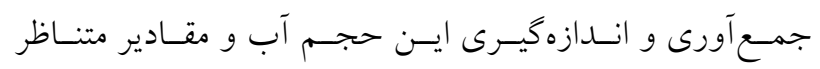

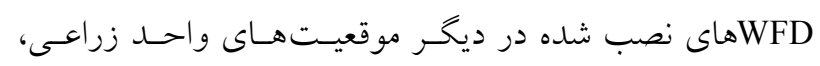

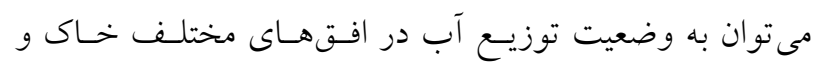

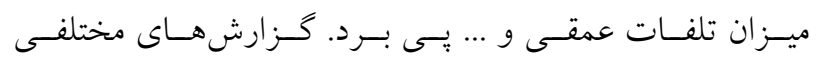

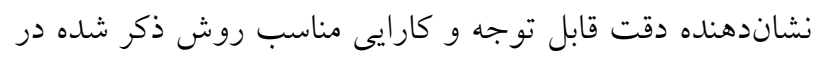
برنامهريزى دقيق آبيارى است (I (I).

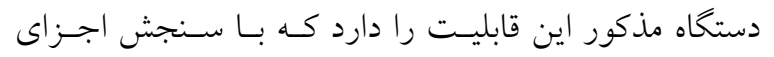

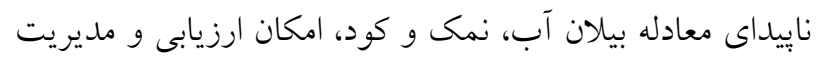

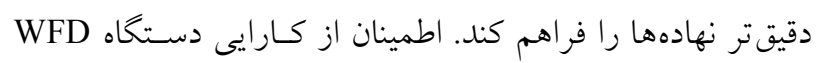

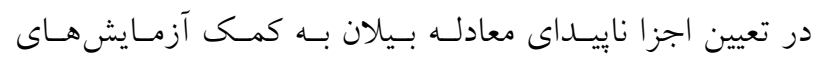

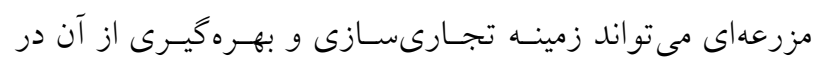
كاربرى هاى مذكور در مقياس وسيع را آسان تر كند (Y I I). تعيين

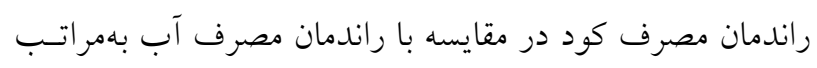

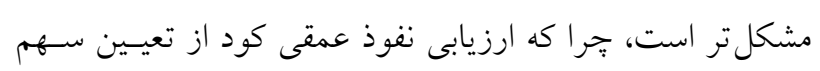

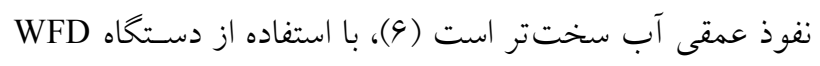

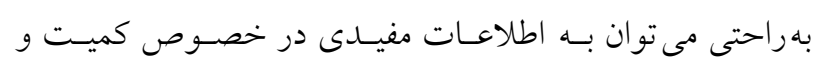

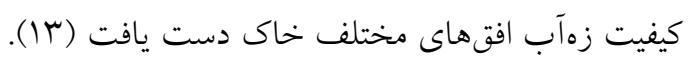

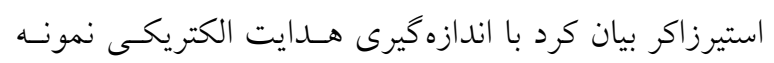

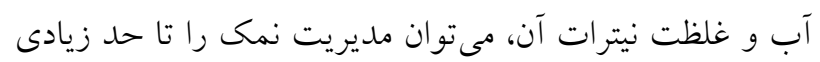

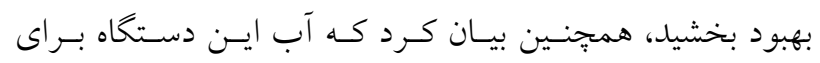
نظارت بر حركت نيترات در منطقـهـ ريشـهـ مـورد اسـتفاده قـرار

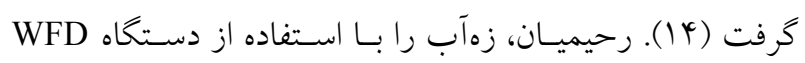

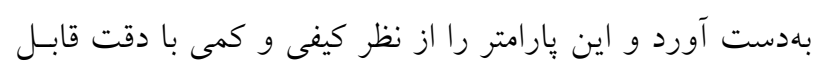
قبولى محاسبه كرد (r).

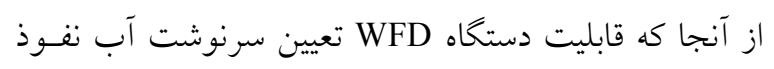
يافته به خاى (سنجش ميزان آب ذخيره شده در ناحيسه ريشـه و

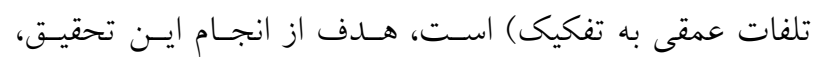

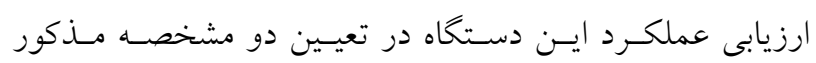

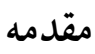

مسئله بحر ان آب در سال هاى اخير و مصرف بيش از ه ل درصــ

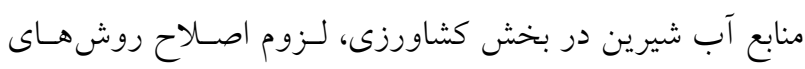

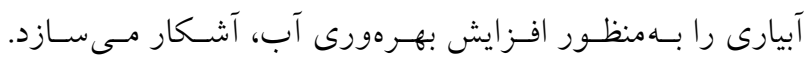

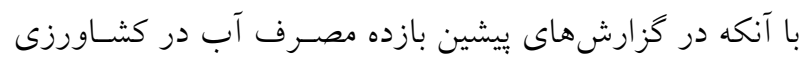

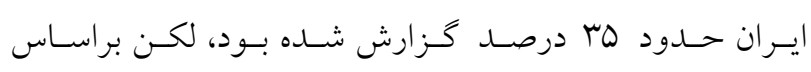

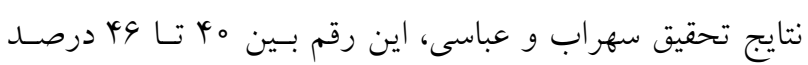

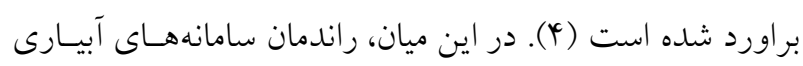

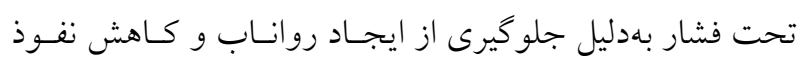

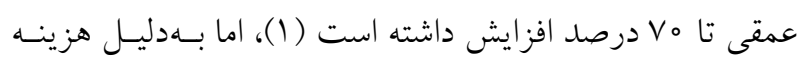
بالاى اجراى سـامانههـاى تحـت فشــار و نيـاز بــه نيـروى كـار

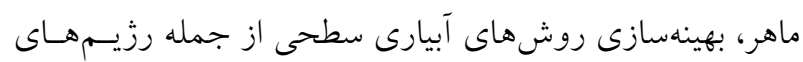

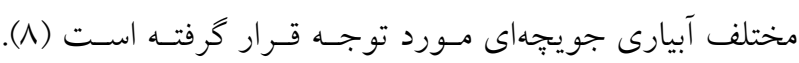

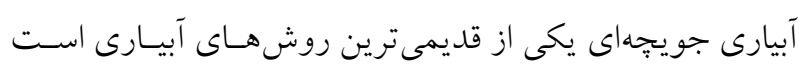

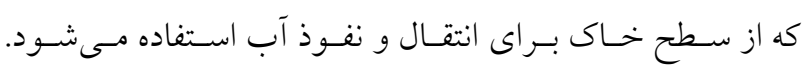

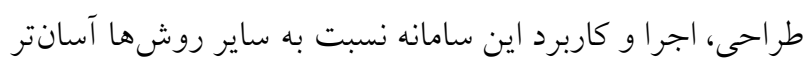
است (ه و 9).

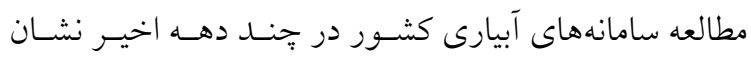

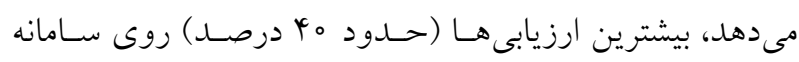

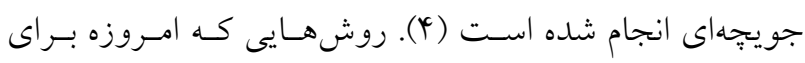

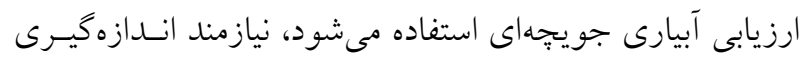

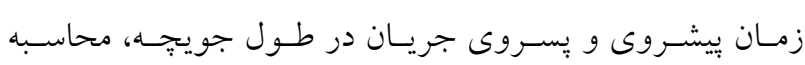

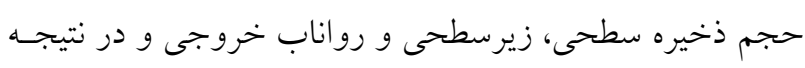

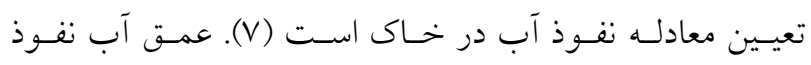

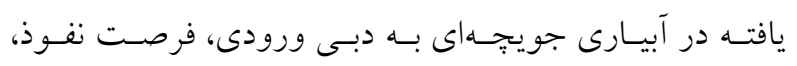

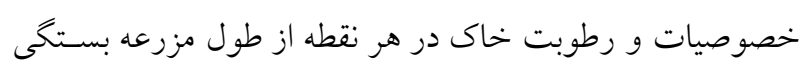
دارد (10) (1.) (1) آبيارى زمين معمولاً با اندازه كيرى و يسيش بينسى كمبـود آب

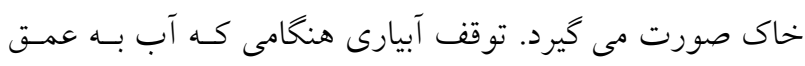

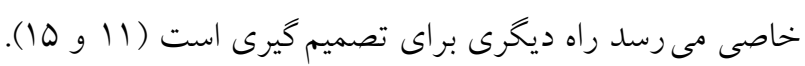

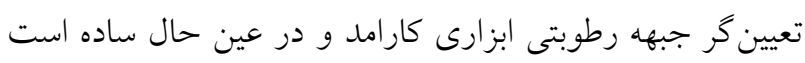

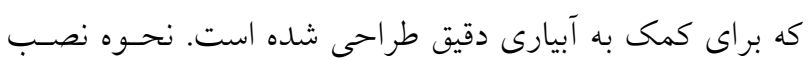




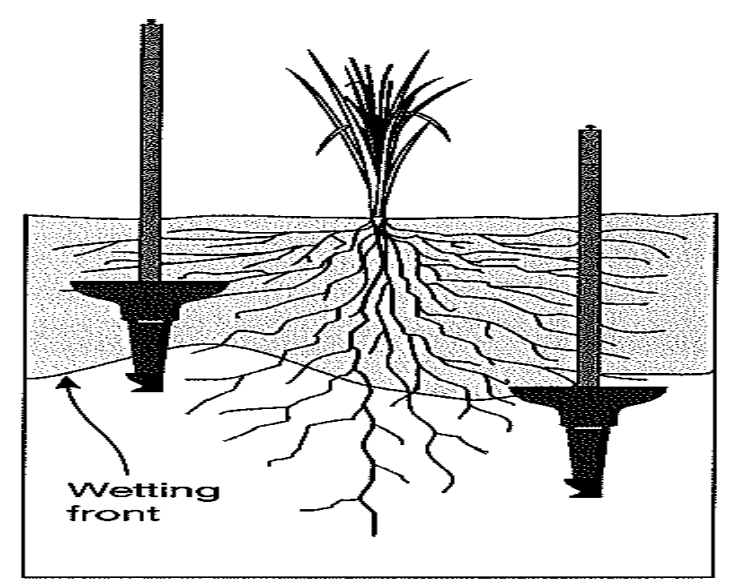

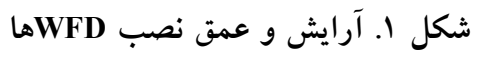

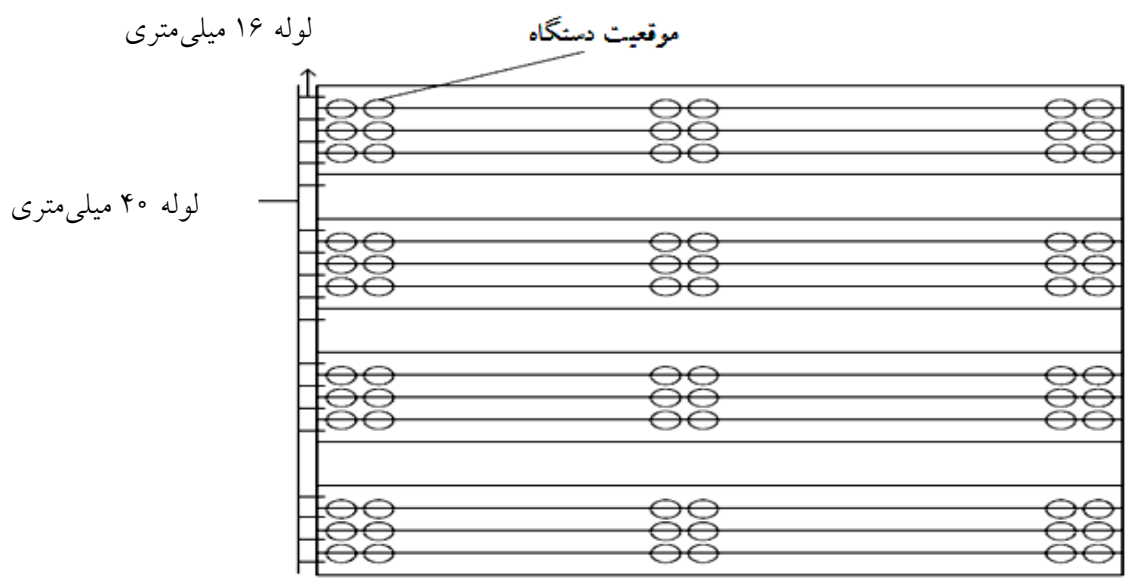

شكل r. بِلان جانمايى طرح اجر اشده در مزرعه آزمايشى

حذف اثرات حاشيهاى، كرتهاى مربوط به هـر تيمـار آبـى در

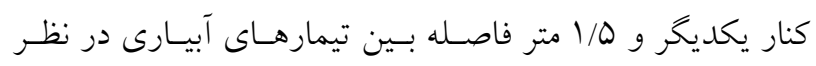

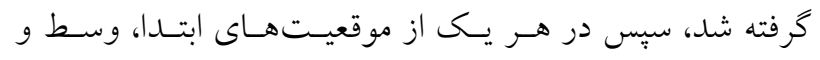

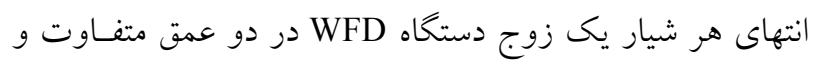

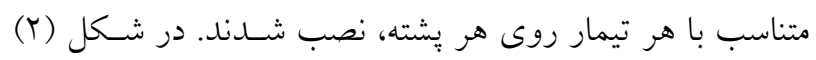

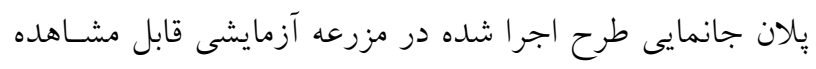

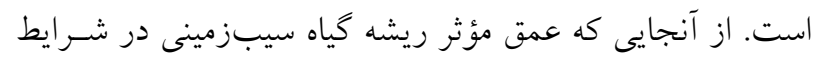

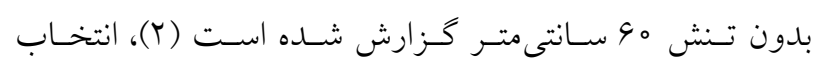

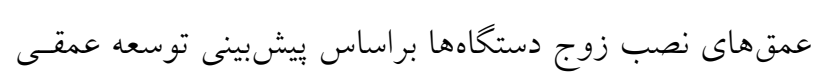

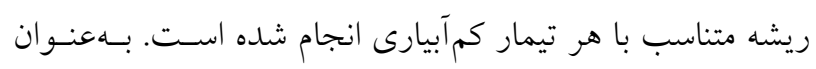
مثال، عمق نصب دستخاه WFD تحتانى و فوقـانى بـراى تيمـار

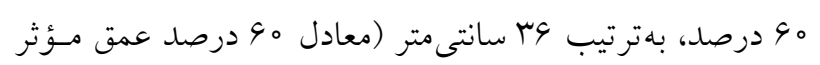

بهعنوان اجزاى زيرسطحى و ناييداى معادلـه بـيلان و همجنـسين نحوه توزيع آب در طول شيار است.

مواد و روشها

اين يزوهش در قالب طرح بلوكهاى كامـل تصـادفى بــا جهــار

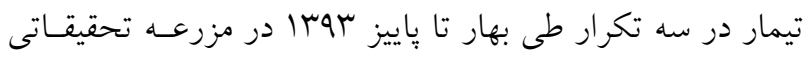

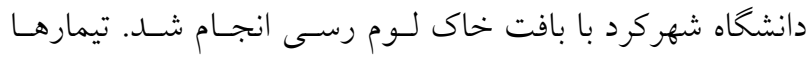

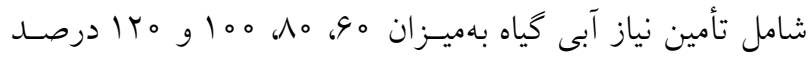

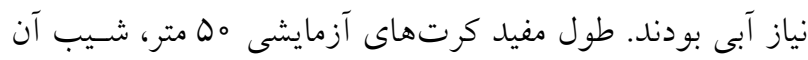

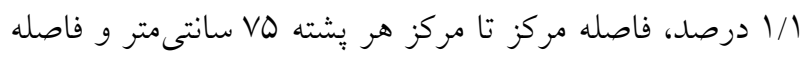

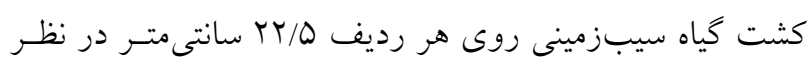

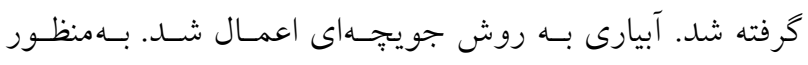


محاسبه شد:

$\mathrm{D}_{\mathrm{n}}=\frac{\left(\mathrm{FC}-\theta_{\mathrm{s}}\right)}{100} \times \mathrm{P} \times \mathrm{D}_{\mathrm{r}}$

در اين رابطه Dn مقدار آب آبيـارى برحسب سـانتىمتر (cm)، FC

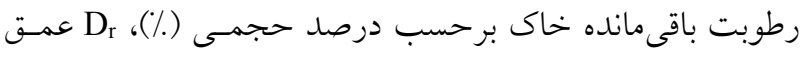

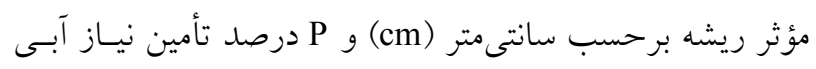
متناظر با هر تيمار برحسب درصد (.) است. با اعمال مديريت آبيارى تشريح شده، فاصله بين دو آبيـارى

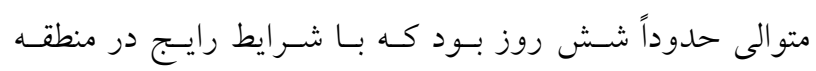

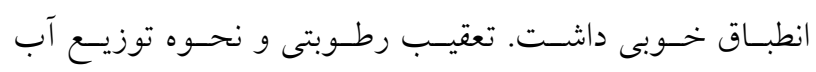

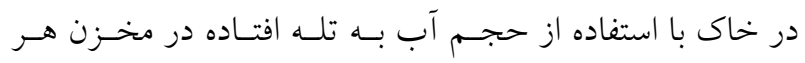
دستخاه و به كمك داده هاى دبى ورودى (سنجش شده با كنتور) انجام شد و براى محاسبه تلفات عمقى و سطحى بهكـار گرفتـه

شدند.

\section{محاسبه عمق آب نفوذ يافته به خاك و سهم تلفات عمقى} به كمـى دادههـاى دسـتخاههـاى WFD عمـق آب نفـوذ يافتـه

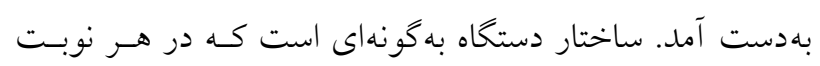

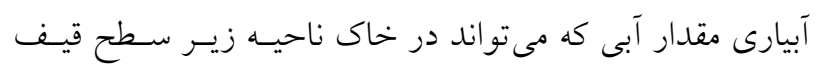
ذخيره شود، توسط اين قيف تله|ندازى شده و در مخزن دستخاه

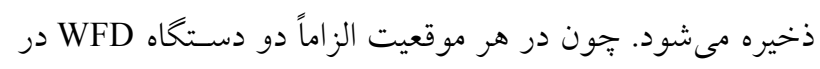

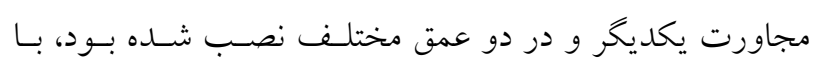

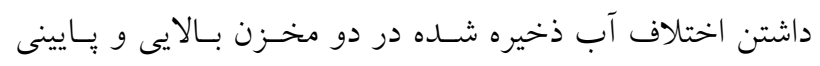
مربوط به هر جفت دستخاه، ميـزان آب ذخيـره شـده در خـاك، واقع در حد فاصل نصب اين دو دستخاه بهراحتى محاسبه شـد.

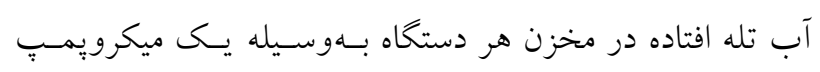

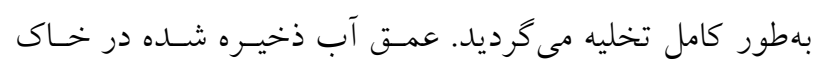
واقع در حد فاصل نصب دو دستخاه مجاور از تقسيم حجم آب لب دمدئ به تله افتاده در مخزن بر مساحت مفيد قيف تلهاندازى محاسـبه

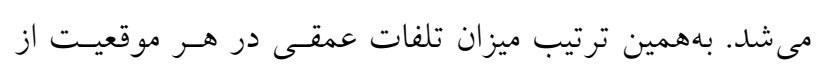

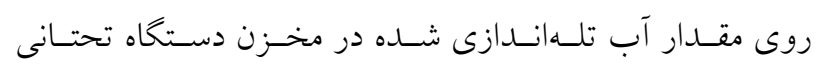

$$
\text { محاسبه و تعيين شد. }
$$

ريشه در تيمار شاهد) و 1/ سانتى متـر (مركـز يــيشبينسى شـده فعاليت ريشه در تيمار مربوطه) اختيار شدند. عمـق نصسب زوج

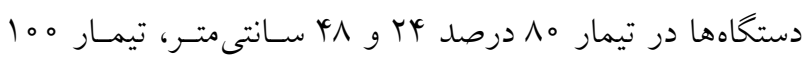

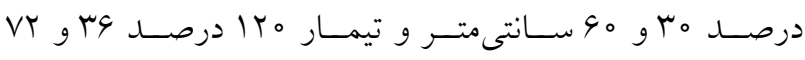
سانتى متر در نظر كرفته شد. لازم بهذكـر اسـت كــه از دادههـاى

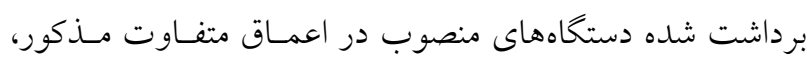

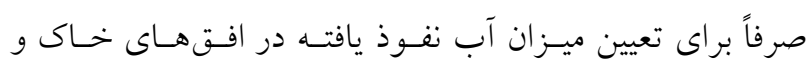
تعقيب و رسيم يروفيل عمقى رطوبـت در طـول شـيار اسـتفاده شده است درحالى كه در تمام تيمارها ميزان آب راه يافته به زيـر افق هو سانتى متر بهعنوان سهم تلفات عمقى محسوب شدهاند. بهاجز عمليات آبيـارى كـه مطـابق مقــادير ذكـر شــده بــراى

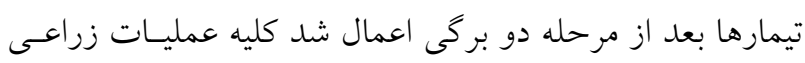
در دوره كشت در تيمارها يكسان بهكار گرفته شد. آبيارىهـا بـا

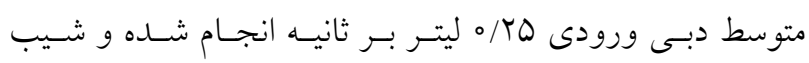

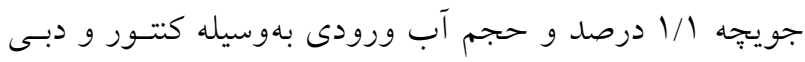
رواناب خروجى از انتهاى شيار بهوسيله فلـوم WSC-I ســنش بـ

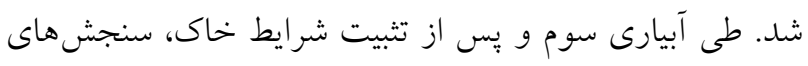

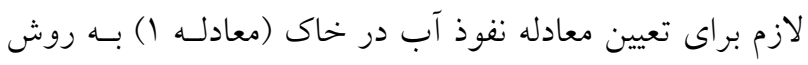
دونقطهاى اليوت بهدست آمد.

$\mathrm{Z}=\circ / \circ \circ \mathrm{\mu} \times \mathrm{t}^{\circ / \mathrm{r} \omega}+\circ / \circ \circ \circ 1 \mathrm{r} \Lambda \times \mathrm{t}$

در اين رابطه Z عمق نفوذ كـرده برحسب سـانتى متـر (cm) و t مدت زمان نفوذ برحسب دقيقه (min) است. حدود رطوبتى ظرفيت زراعى و نقطه يزّمردى دائم خاى با استفاده از دستخاه صفحات فشارى تعيين و مقادير آنها بهترتيب

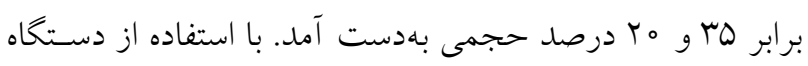

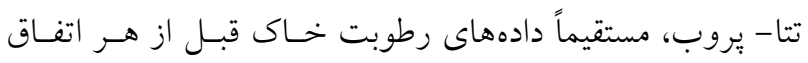

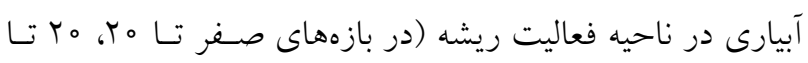

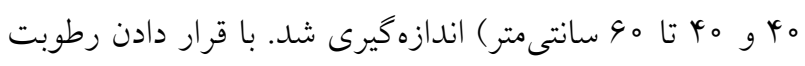
باقى مانده خاى در هر تيمار قبل از هر نوبـت آبيـارى و درصــ

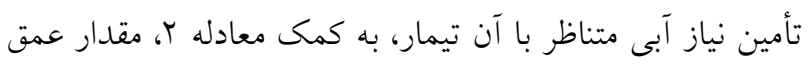
آب آبيارى براى تيمارهاى مختلف تعيين شد. سيس بـا اسـتفاده

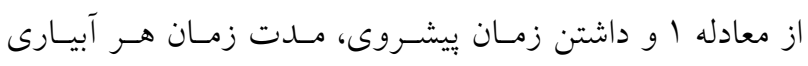




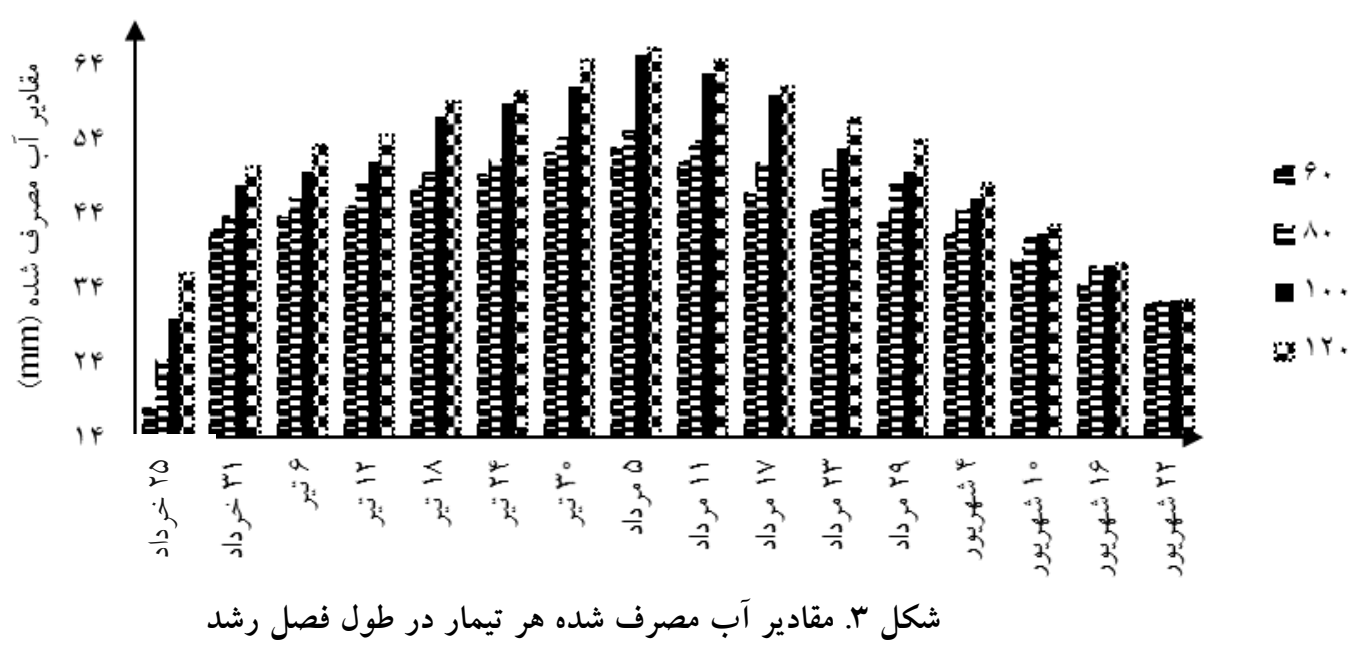

عدد يك نزديكتر باشد، بيـانكر تقـارب بيشـتر بـوده و مقـادير

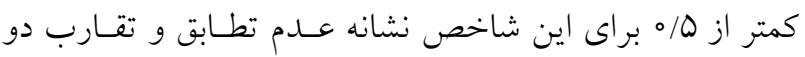

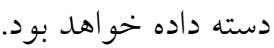
$N S=1-\sum\left(\frac{\left(x_{i}-x_{0}\right)^{r}}{\left(x_{i}-\bar{x}\right)^{r}}\right)$

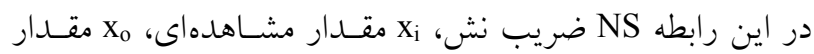

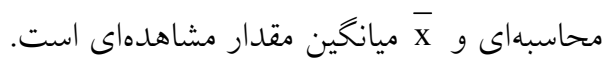

\section{نتايج و بحث} مقادير آب به كار رفته در عمليات آبيارى اعمال درصدهاى آبيارى و محاسبه طول مدت آبيـارى مستلزم

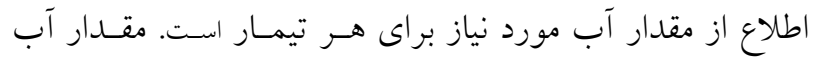
آبيارى براى هر تيمار متناسب بـا كمبـود رطوبـت آن تيمـار بـا

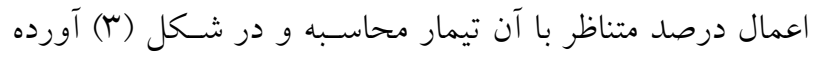

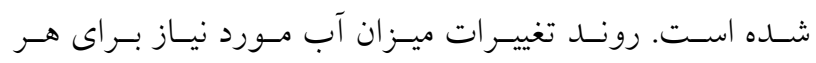
تيمار در طول فصل كشت با روند تغييرات رطوبت بـاقىمانــده

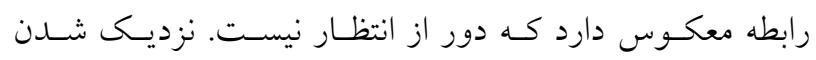

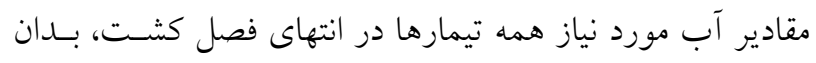

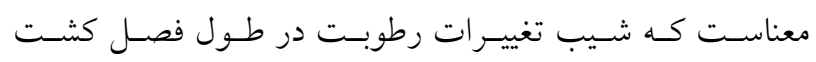

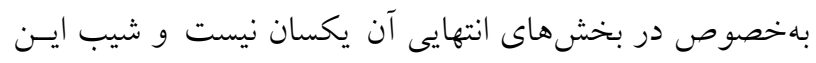

اندازهگيرى و محاسبه رطوبت ذخيره شده در خاك

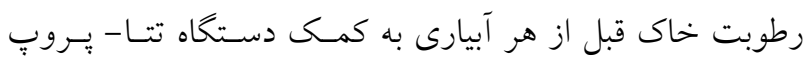

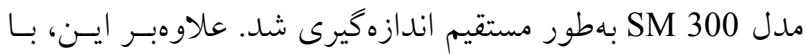

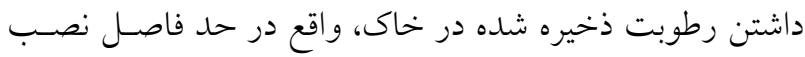

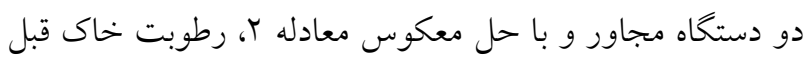
از عمليات آبيارى محاسبه شد.

اندازهيرى و محاسبه تلفات سطحى

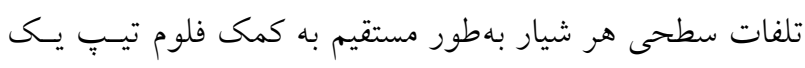

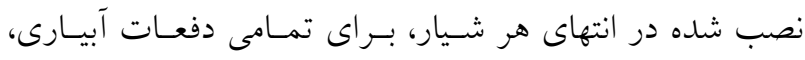

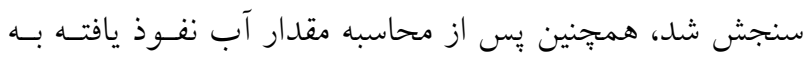

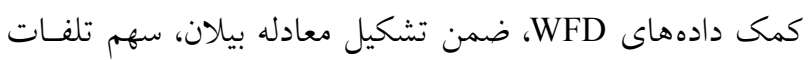
سطحى جهت كنترل براورد شد. ارزيابى عملكرد دستخاه WFD

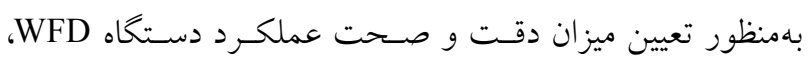

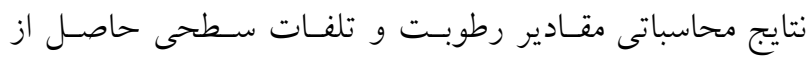

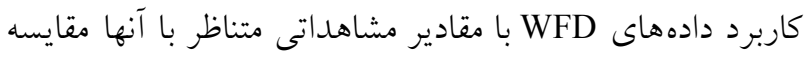

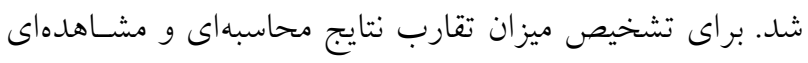

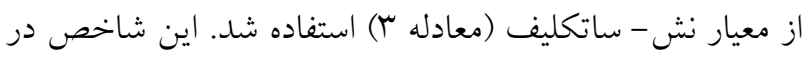

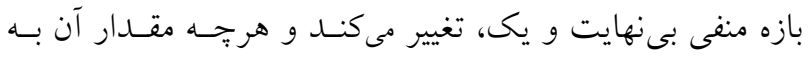




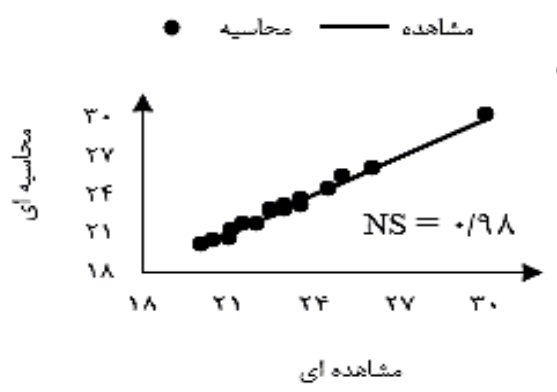

(ب)

- مشايمدي

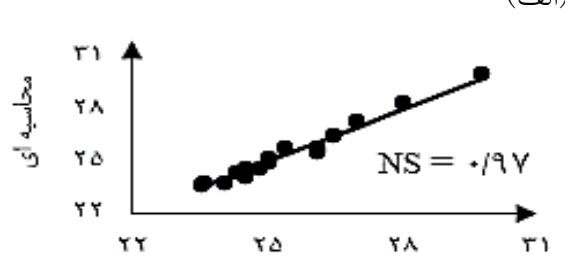

مساهدة اي

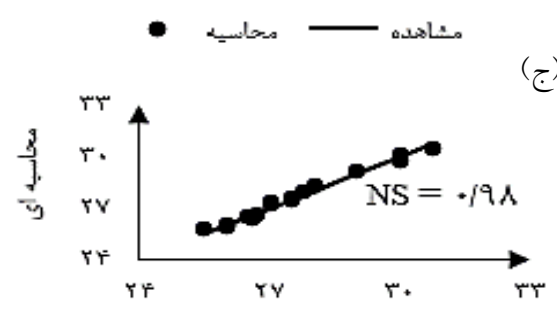

مشاهدة اى

شكل f. مقايسه رطوبت اندازهيرى شده و محاسبه شده در طول فصل براى تيمارهاى

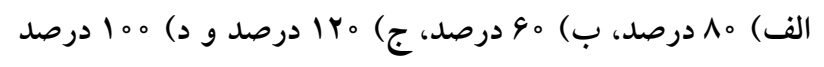

كمى دادههاى WFD، در كليه تيمارها مربوط بـه تمـام دفعـات

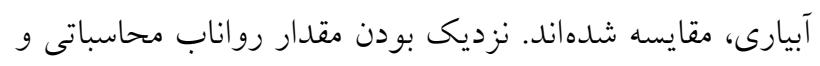

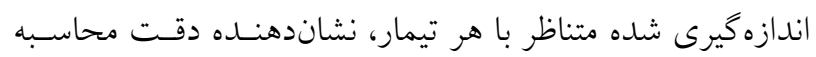

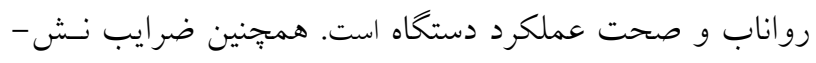

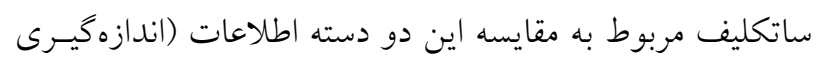

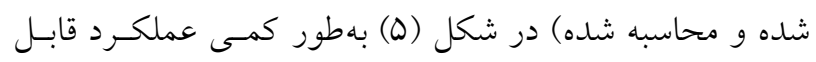
قبول دستخاه WFD را تأييد مى كند.

\section{مقادير تلفات عمقى}

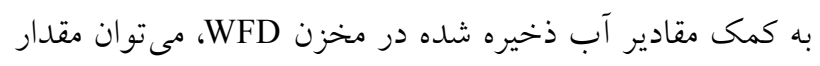

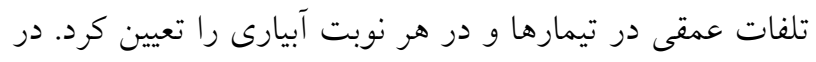

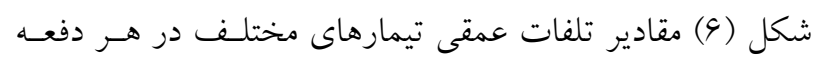

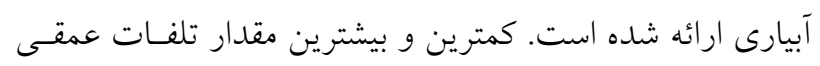

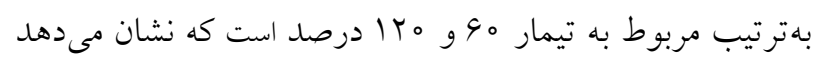

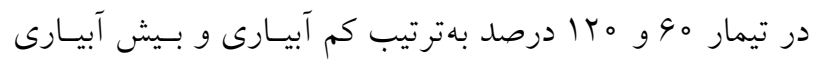
اتفاق افتاده است. تلفات عمقى در نيم دوره اول فصل كشت (از
تغييرات رابطه معكوس با درصد تأمين رطوبت اعمـال شــه در هر تيمار دارد.

كـاربرد دادههـاى دسـتخاه WFD بــراى محاسـبه رطوبـت باقىمانده قبل از آبيارى

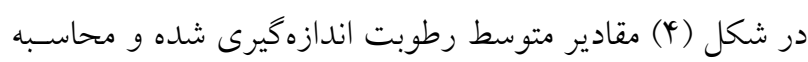
شده در كليه تيمارها، مربوط به كليه دفعات آبيـارى، نشـان داده

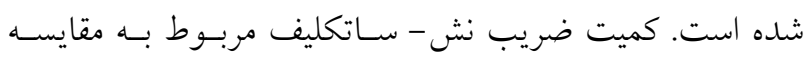

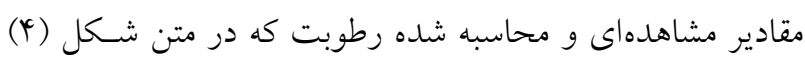

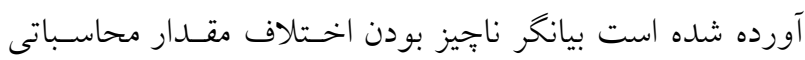
(كه به كمك دادههاى دستخاه WFD بـهدسـت آمــده) و مقـدار

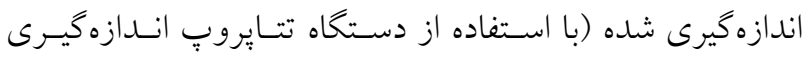
شده) و نشاندهنده كارا بودن دستخاه است. كاربرد دادههاى دستخاه WFD براى محاسبه رواناب انتهايى در شكل (ه) مقدار رواناب اندازهيرى شده و محاسبه شده بـهـ 


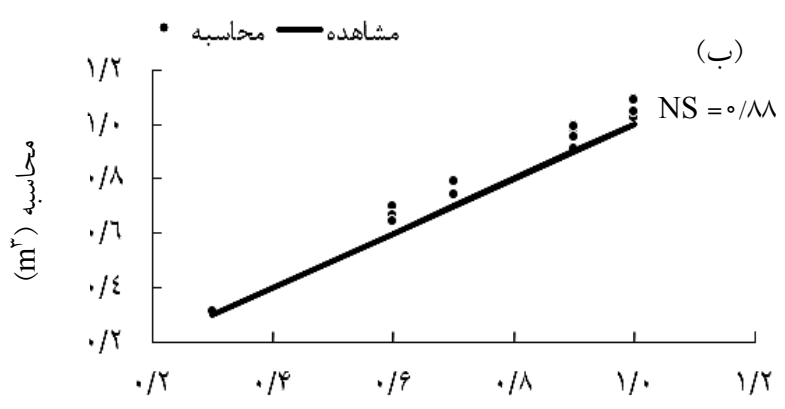

مشاهده

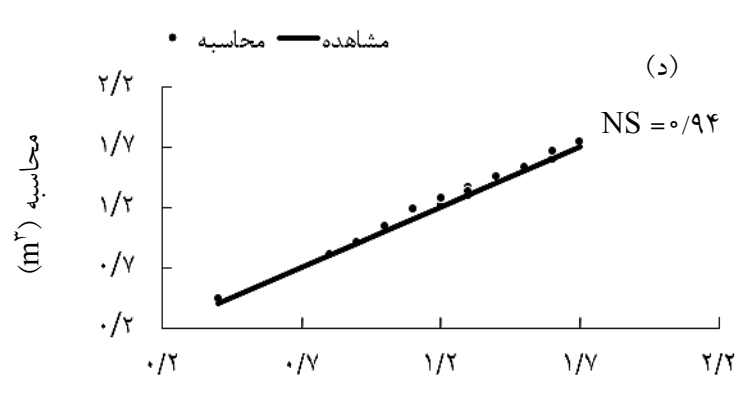

مشاهده

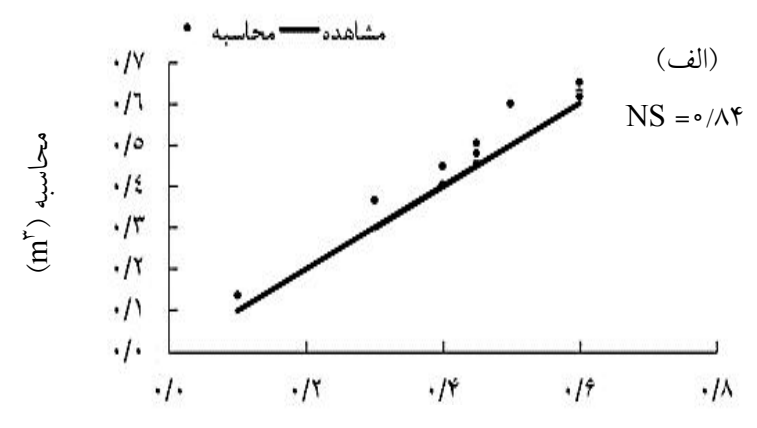

مشاهده (m)

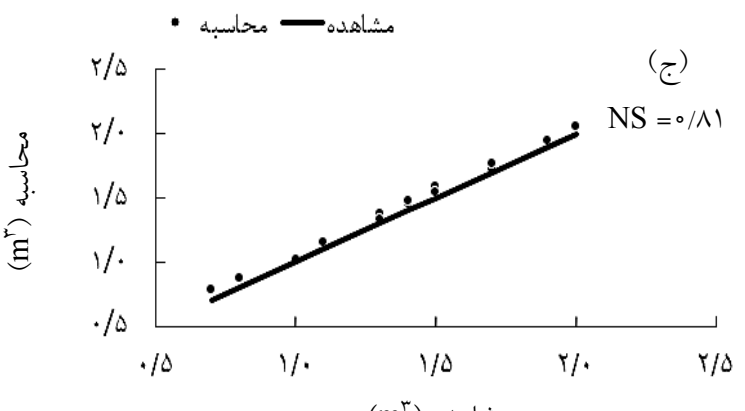

$\left(\mathrm{m}^{r}\right)$ مشاهد

شكل ه. مقايسه رواناب اندازهيرى شده و محاسبه شده در طول فصل براى تيمارهاى

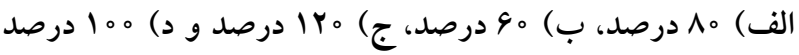

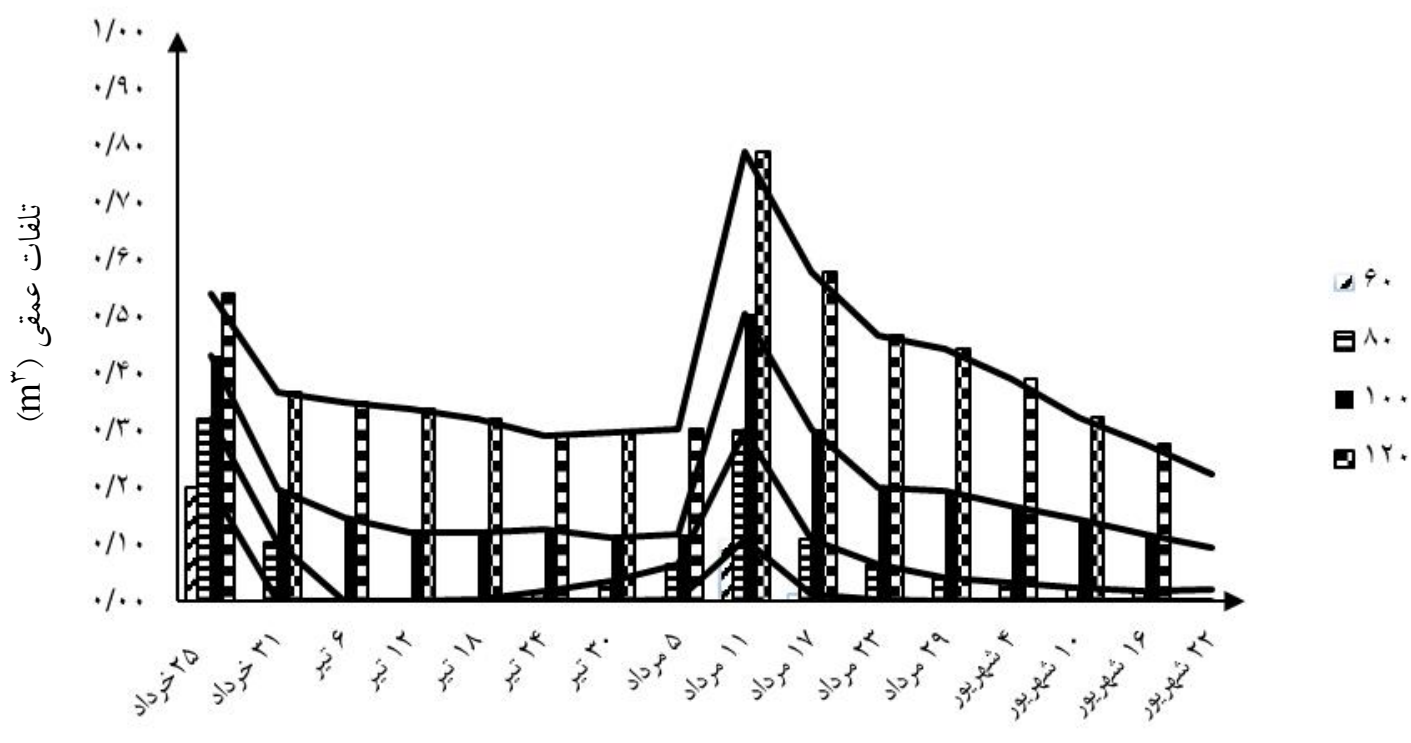

شكل 9. مقادير تلفات عمقى مربوط به تيمارهاى مختلف در طول فصل كشت

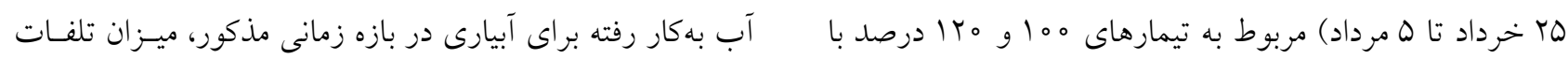

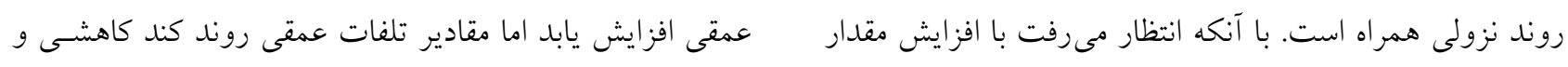




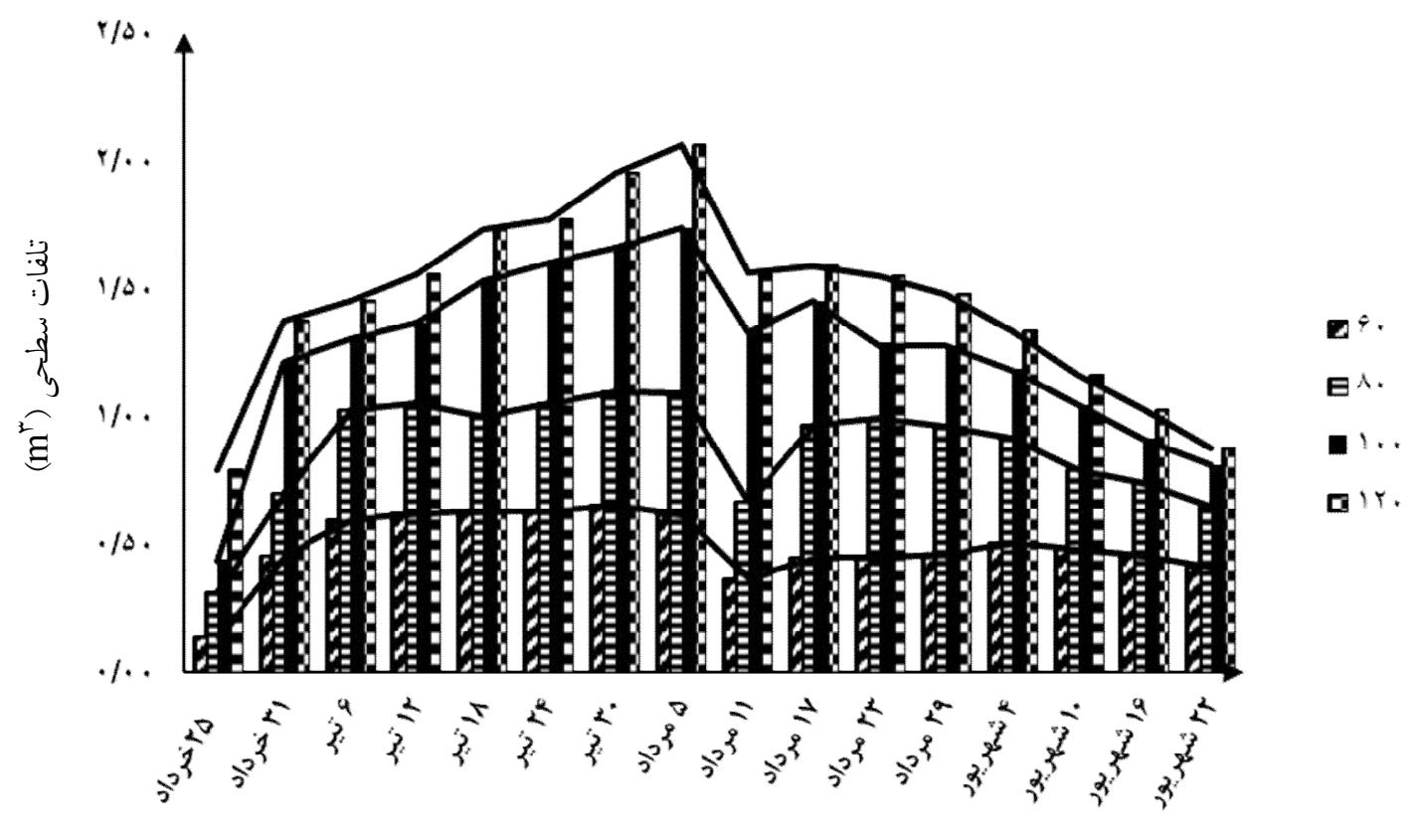

شكل V. مقادير تلفات سطحى در تيمارهاى مختلف

دادههاى WFD قابل اندازه كيرى يا محاسبه هستند، لذا مىتـوان

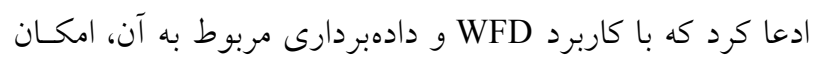

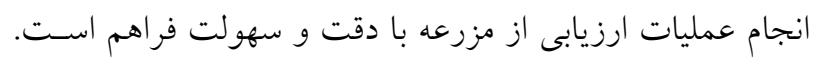

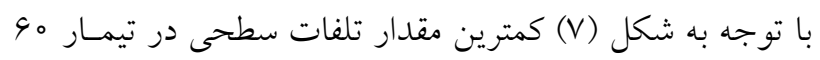
درصد و بيشترين تلفات در تيمار ه Y ا درصد بروز يافته اسـت.

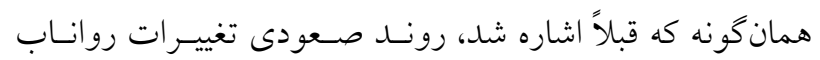

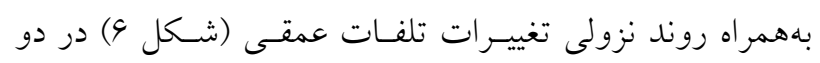

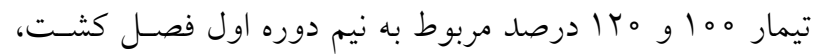
نشاندهنده تثبيت بستر خاك و كاهش جزئى نفوذيذيرى اسـت،

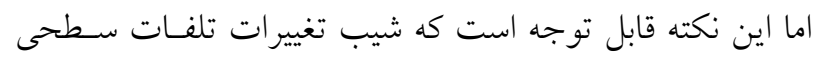

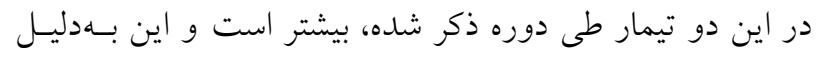

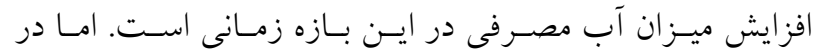

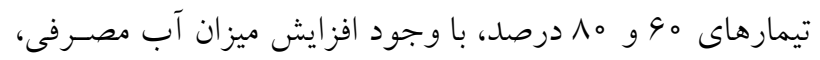
ميزان رواناب در دوره اول كشت تغيير نكرده است كه دليـل آن

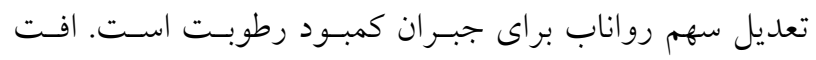

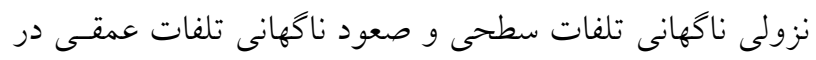

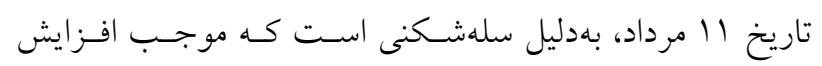

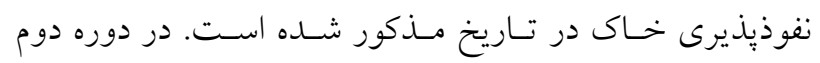

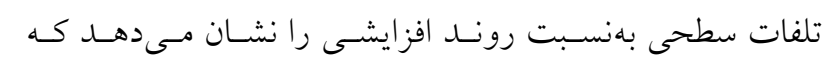

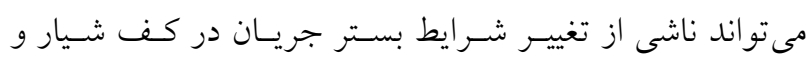

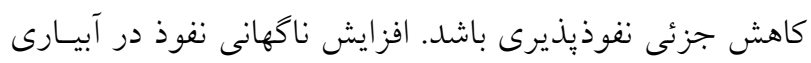

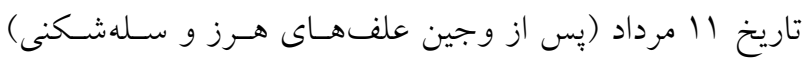

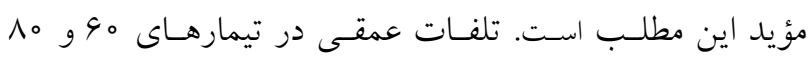

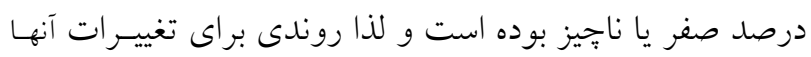

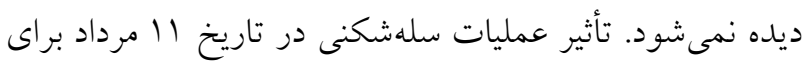
همه تيمارها در شكل (V) مشهود است. در نيم دوره دوم فصل نسل

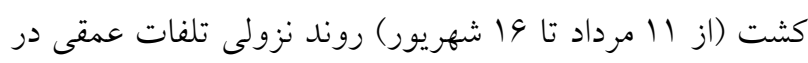
تيمارهاى مختلف مشاهده مى شود كه متناسب با كـاهش مقــدار آب مورد نياز در اين دوره از كشت بودهه و قابل انتظار است.

مقادير تلفات سطحى

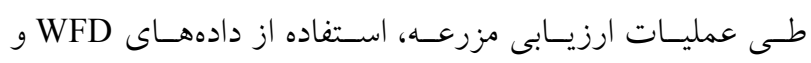

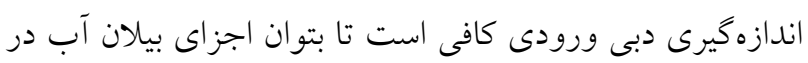

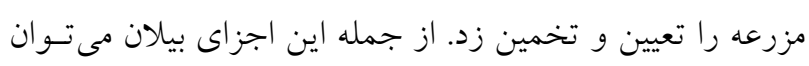

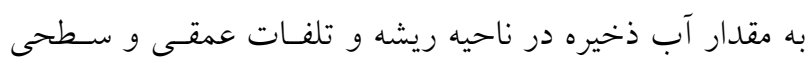

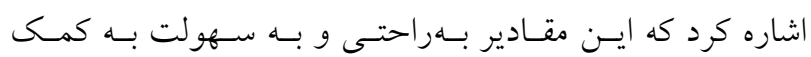




$$
\begin{aligned}
& \text { سهولت، دادههاى مربوط به اجزاى ناييداى معادله بيلان را تعيين } \\
& \text { كرد. با معلوم شدن اين اجزا، امكان برآورد ميزان تلفات عمقىى } \\
& \text { و حتى سطحى فراهم شده و توزيع طولى و عمقى رطوبـت در }
\end{aligned}
$$

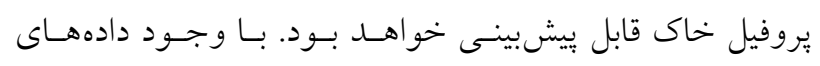

$$
\begin{aligned}
& \text { مـذكور در كنـار دادههـاى جريـان ورودىى انـدازهذيـرى شـده، }
\end{aligned}
$$

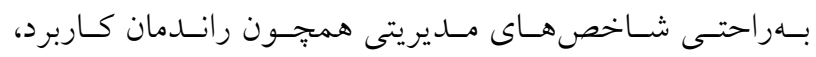

$$
\begin{aligned}
& \text { يكنواختى توزيع و كفايـت آبيـارى قابـل تعيـين بــوده و امكـان } \\
& \text { ارزيابى سريع و صريح عملكرد سيستم آبيـارى فـراهم خواهـد } \\
& \text { بود. } \\
& \text { كشت، تغييرات تلفات سطحى در تيمارهاى مختلـف بـا ميـزان } \\
& \text { تنيجه كيرى } \\
& \text { در اين بززوهش، نتايج حاصل از مقايسـه مقـادير محاسـبه شـده }
\end{aligned}
$$

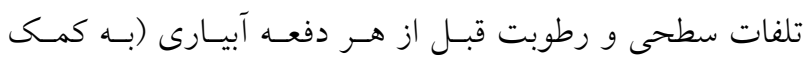

$$
\begin{aligned}
& \text { دادههاى دستخاه WFD) با مقادير متناظر اندازه گيرى شـده ايسن } \\
& \text { دو يارامتر، نزديكى خوبى را نشان مىدهد كه بيانكننده دقـت و }
\end{aligned}
$$

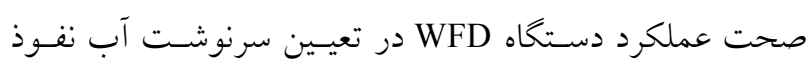

$$
\begin{aligned}
& \text { يافته به خاك است. با وجود دادههاى دستگاه WFD مى توان بـه }
\end{aligned}
$$

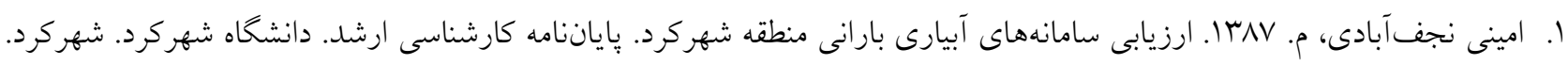

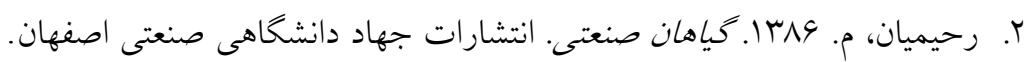

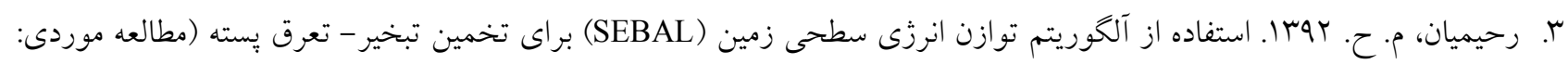

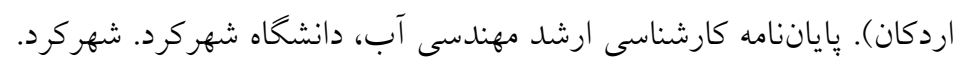

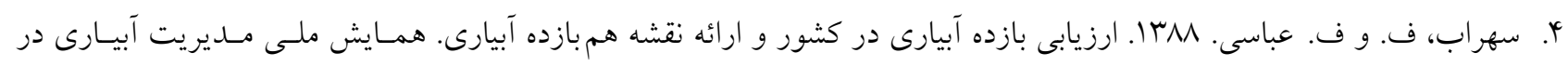

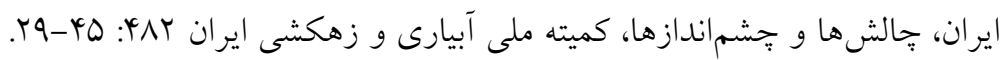

5. Biswas, T. K., G. Schrale and R. Stirzaker. 2008. New tools and methodologies for in situ monitoring of root zone salinity and leaching efficiency under drip and sprinkler irrigation. Acta Horticulturae 792: 115-122.

6. Burguete, J., N. Zapata. P. Garcia-Navarro. M. Maikaka. E. Playan and J. Murillo. 2009. Fertigation in furrow and level furrow system. II. Model calibration and practical application. Irrigation and Drainage Engineering, ASCE 135: 413-420.

7. Ebrahimian, H. and A. M. Liaghat. 2011. Field evaluation of various mathematical models for furrow and border irrigation systems. Soil and Water Research 6(2): 91-101.

8. Elliot, R. L. and W. R. Walker. 1982. Field evaluation of furrow infiltration and advance functions. Trans, ASAE 25(2): 396-400.

9. Holzapfel, E. A., C. Leiva, M. A. Marino, J. Paredes, J. L. Arumi and M. Billib. 2010. Furrow irrigation management and design criteria using efficiency parameters and simulation models. Chilean Journal of Agricultural Research 70(2): 287-296.

10. Mostafazadeh, B. and W. R. Walker. 1981. Furrow geometry under surge and continuous flow. Iran Agricultural Research 6(2): 57-71.

11. Oyonarte, N. A., L. Mateos and M. J. Palomo. 2002. Infiltration variability in furrow irrigation. Journal of Irrigation and Drainage Engineering 128(1): 26-33.

12. Stirzaker, R. J. 2003. When to turn the water off: scheduling micro-irrigation with a wetting front detector. Irrigation Science 22: 177-185.

13. Stirzaker, R. J. and P. A. Hutchinson. 2005. Irrigation controlled by a wetting front detector: field evaluation under sprinkler irrigation. Australian Journal of Soil Research 43: 935-943.

14. Stirzaker R. J., P. A. Hutchinson and M. L. Mosena. 2000. A new way for small farm irrigators to save water. In: Proceedings of the $6^{\text {th }}$ International Micro-Irrigation Congress Cape Town, South Africa.

15.Zur, B., U. Ben-Hanan, A. Rimmer and A. Yardeni. 1994. Control of irrigation amounts using the velocity and position of wetting front. Irrigation Science 14: 207-212. 


\title{
Efficiency of WFD Device Performance to Determine the Water Balance Components Infiltrating to the Root Zone
}

\author{
M. Raeisi Asadabadi*, M. R. Nouri Emamzadehi and R. Fattahi Nafchi ${ }^{1}$
}

(Received: March 9-2016; Accepted: August 28-2017)

\begin{abstract}
In order to optimize the irrigation system performance, it is essential to get information about water balance components in the farm. So, the objective of this study was evaluating the performance of the WFD device in determining water penetrated fate in the soil at each irrigation occurrence as one of the important components in evaluating the irrigation water efficiency. By having the water amount infiltrated in the root zone and the deep percolation amount collected and determined by WFD device, contribution of surface losses related to every irrigation occurrence can be determined by the employing water balance equation. This research was carried out in the form of completely randomized design blocks in three replications and under the treatments of 60, 80, 100 and $120 \%$ of the irrigation requirement supply of a potato plant in the research farm of Shahr-e Kord University in 2014. To gather the growing season data, before the planting operation, various WFD devices were installed at different depths and locations along furrow. In addition to WFD data, input discharge (using counter), output discharge (measured by flume type 1) and values of soil moisture (theta-probe device) were collected during the harvesting season. The results showed that the mean Nash-Satcliffe coefficient of comparison between the values of calculated and measured surface losses corresponding to it, and also comparison of the values of the calculated and measured residual moisture before each irrigation occurrence were obtained to be 0.87 and 0.98 , respectively. Quantity of this indicator in the two conducted comparisons represented the correct and exact performance of the WFD device in the farm operation evaluation. During the farm evaluation process under the experimental furrow, distribution uniformity averages in the experimental treatments were acquired to be $75.56,83.78,88.06$, and $90.34 \%$, respectively. Likewise, water amount average percolation of root zone (depth losses) in experimental treatments at each irrigation occurrence was measured to be $0.02,0.07,0.27$ and $0.47 \mathrm{~m}^{3}$ for each furrow.
\end{abstract}

Keywords: Surface losses, Depth losses, Water balance

1. Water Engineering Department, Faculty of Agriculture, Shahrekord University, Shahrekord, Iran.

*: Corresponding Author, Email: Siavash_1370614@yahoo.com 